\title{
Jogo educativo como estratégia de educação em saúde para pessoas vivendo com HIV/AIDS
}

\author{
Educative game as educational strategy in healthcare for \\ people with HIV/AIDS
}

\begin{abstract}
Bruna Roberta Paixão dos Santos', Danielle Oliveira Maciel', Celyce Agrassar da Silva', Maria de Nazareth de Lima Carneiro', João Gabriel Pinto Gursen', Lucas Ribeiro Brito', Maryllia Suellem Almeida Cesario', Suzanne Camila Ferreira de Ferreira',

Elza Sara Maués Pena', Arthur dos Santos Baía', Mariana Zuleica Corrêa Massoud', Julie Ane da Silva Formigosa², Danielle Saraiva Tuma dos Reis ${ }^{1}$

'Residência Multiprofissional em Atenção ao Paciente Crítico, Hospital Universitário João de Barros Barreto, Universidade Federal do Pará, Belém (PA), Brasil.

${ }^{2}$ Residência Uniprofissional em Enfermagem Oncológica, Hospital Ophir Loyola, Universidade Estadual do Pará, Belém (PA), Brasil.
\end{abstract}

\section{RESUMO}

Contextualização: A utilização de uma estratégia pedagógica no formato de jogo revela-se alternativa com potencial para instaurar uma vertente problematizadora, capaz de mobilizar os jogadores a partir de suas necessidades e experiências. Descrição da experiência: Trata-se de um relato de experiência vivenciado por residentes do Programa de Residência Multiprofissional em Atenção ao Paciente Crítico. Participaram da ação educativa aproximadamente 40 pessoas vivendo com HIV/aids, em tratamento para a doença, aguardando na sala de espera consulta com equipe multiprofissional em um serviço de referência em atendimento HIV/aids, localizado no município de Belém/PA. Utilizou-se como ferramenta educativa um jogo de fácil manuseio para a participação dos usuários, denominado de "Roleta da Saúde". Considerações finais: A aplicação de tecnologia educativa como estratégia educacional em saúde para o grupo de pessoas convivendo com HIV/ aids demonstrou-se exitosa por favorecer a troca de informações e a reflexão acerca do tema. Os participantes da ação educativa puderam esclarecer dúvidas e interagir de modo descontraído, facilitando a participação de todos no processo de aprendizagem.

PALAVRAS-CHAVE: Educação em saúde. HIV. Síndrome da Imunodeficiência Adquirida. Equipe multiprofissional.

Recebido: Ago.17, 2017 Aceito: Out. 23, 2018

\section{COMO CITAR ESTE ARTIGO} Santos BRP, Maciel DO, Silva CA, et al. Jogo educativo como estratégia de educação em saúde para pessoas vivendo com HIV/AIDS. Interdisciplinary Journal of Health Education. 2019 Jan-Dez:4(1-2):49-54 https://doi.org/10.4322/ijhe.2018.014

\section{CORRESPONDÊNCIA}

Bruna Roberta Paixão dos Santos Universidade Federal do Pará Av. Augusto Montenegro, 4900, Casa 305, Parque Verde, CEP 66635-110, Belém (PA), Brasil brunapaixaoo@gmail.com

\section{FONTE DE FINANCIAMENTO}

Nenhuma.

\section{CONFLITO DE INTERESSE}

Os autores declararam não

haver conflitos de interesse.

O estudo foi realizado na cidade de Belém (PA), Brasil.

Todos os autores leram e aprovam a versão final submetida ao Interdisciplinary Journal of Health Education (IJHE).

\section{ABSTRACT}

Contextualization: The use of a pedagogical strategy in the game format reveals an alternative with the potential to establish a problematizing aspect, able to mobilize the players in their needs and experiences. Description of the experience: This is an experience report by residents of the Multiprofessional Residency Program in Care of the Critical Patient. During the educative activity, the treatment was applied for 40 people with HIV/aids in treatment for the disease waiting in the waiting room consultation with multiprofessional team in a referral service in HIV / aids care, located in the city of Belém / PA. An educational tool was an easy-to-use game for user participation, called "Roleta da Saúde". Final considerations: The application of educational technology as an educational strategy in health for the group of people living with HIV / AIDS has proved successful because it favors the exchange of information and reflection on the subject. The participants of the educational action were able to clarify doubts and interact in a relaxed way, facilitating the participation of all in the learning process.

KEYWORDS: Health education. HIV. Acquired Immunodeficiency Syndrome. Multiprofissional team. 


\section{Contextualização}

$\mathrm{O}$ vírus da imunodeficiência humana (HIV) é o agente etiológico causador da Síndrome da Imunodeficiência adquirida (AIDS), o qual ataca os linfócitos TCD4+ infectando as células de defesa do organismo. O mesmo altera o DNA celular e instala-se, iniciando o processo de multiplicação e comprometimento do sistema de proteção do indivíduo. Com a multiplicação viral, os linfócitos são rompidos liberando novos vírus que estarão prontos para infectar novas células, levando à progressão da infecção $o^{1-3}$.

A AIDS constitui-se na atualidade um dos maiores e mais graves problemas de saúde pública no Brasil e no mundo ${ }^{4}$. A epidemia global dessa doença teve seu início em 1981, quando começaram a surgir pacientes do sexo masculino nos Estados Unidos e no Brasil, desde o início da epidemia até dezembro de 2015, já foram identificados 303.353 óbitos $^{5}$. Recentemente, entre os anos de 2007 a junho de 2016 foram notificados 136.945 casos de infecção pelo Vírus da Imunodeficiência Humana (HIV) no Brasil, sendo 71.396 casos no Sudeste (52,1\%), 28.879 no Sul $(21,1 \%), 18.840$ no Nordeste $(13,8 \%), 9.152$ no Centro-Oeste $(6,7 \%)$ e 6.868 na Região Norte $(6,3 \%)^{6}$.

No mundo, existem aproximadamente cerca de 34 milhões de Pessoas Vivendo com HIV/aids (PVHAs), representando uma pandemia que se encontra em franco crescimento, tornando-se um desafio para vários setores sociais em relação às medidas de controle das vulnerabilidades envolvidas nos aspectos individuais e contextuais de exposição ao vírus?

Dentre os fatores para a redução dessa pandemia está o acesso mais precoce possível as PVHAs, com o intuito de eliminar a ocorrência de novas infecções e proporcionar maior qualidade de vida para os envolvidos. Nesse sentido, surgiu a ideia das Nações Unidas convocarem os países a implantar, até 2020, programas que possam diagnosticar $90 \%$ das pessoas com $\mathrm{HIV}$, tratar $90 \%$ delas por meio dos antirretrovirais e fazer com que $90 \%$ das pessoas tratadas tenham carga viral indetectável. É uma meta que poderia levar ao fim da epidemia no mundo até $2030^{8-10}$.

Segundo o Ministério da Saúde ${ }^{6}$, uma estratégia para ajudar na redução do número de casos seria a utilização da dimensão educativa, a qual tem o caráter esclarecedor sobre os mais variados tópicos de abordagem ao HIV/aids do Programa NacionalIST/AIDS. A dimensão educativa visa, por exemplo, a transmissão de informações sobre a epidemia do HIV/aids, as formas de transmissão, opções de prevenção disponíveis e os procedimentos pelos quais se dá o tratamento. Salienta-se que o conjunto de informações a ser abordado com um determinado grupo deve ser articulado com os conhecimentos prévios dos usuários, somando-se aos aspectos sociais e contextos de vida dos mesmos. Ainda nessa dimensão, todas as dúvidas relacionadas a cada um dos aspectos, tais como prevenção, transmissão e tratamento, devem ser sanadas. É premente buscar estratégias pedagógicas que não considerem apenas a dimensão cognitiva da aprendizagem, mas estimulem o raciocínio crítico-reflexivo, o favorecimento da interação entre os envolvidos e a produção de modos de subjetivação.

A metodologia ativa vem com uma nova proposta de estratégia de ensino-aprendizagem. É uma concepção educativa que estimula processos construtivos de ação-reflexão-ação. A inserção crítica na realidade confere significado à aprendizagem. O eixo básico de orientação de todo processo refere-se à ação-reflexão-ação transformadora ${ }^{11}$. Nessa perspectiva, a utilização de uma estratégia pedagógica no formato de jogo revela-se alternativa com potencial para instaurar uma vertente problematizadora, capaz de mobilizar os jogadores em seus desejos e suas experiências e favorecer a invenção ${ }^{12,13}$, sendo essa estratégia mencionada nesse estudo para a abordagem em PVHAs.

Os usuários são incentivados a utilizarem seus conhecimentos prévios na resolução das questões elaboradas a partir do jogo, dessa forma, o sujeito participa ativamente 
do processo de ensino-aprendizagem, busca o saber e se apropria do conhecimento, reflete criticamente sobre o que apreendeu para depois realizar ações e transformar a realidade em que vive ${ }^{11}$.

As estratégias para abordagem do público HIV/aids devem considerar o perfil da população e as metas que se pretendem atingir, tendo as atividades em grupo estratégia fundamental uma vez que favorece a experiência coletiva, em que os membros do grupo-alvo são capazes de buscar soluções para o enfrentamento da doença e assim, melhor qualidade de vida ${ }^{14}$.

Nesse sentido, o objetivo deste estudo foi descrever um relato de experiência vivenciado por residentes multiprofissionais em saúde na utilização de um Jogo "Roleta da Saúde" como estratégia educativa para pessoas vivendo com HIV / aids.

\section{Descrição da experiência}

Trata-se de um relato de experiência vivenciado por residentes do Programa de Residência Multiprofissional em Atenção ao Paciente Crítico da Universidade Federal do Pará, que tem o propósito de formar profissionais habilitados a assistir Pacientes em Estado Crítico com enfoque na Atenção Clínica das Doenças Transmissíveis. Consiste em uma pós graduação lato sensu voltada para educação em serviço e destinada às categorias que integram a área da saúde (Enfermagem, Fisioterapia, Psicologia, Nutrição, Farmácia e Odontologia). Durante Treinamento em serviço em um dos cenários de prática da residência, os residentes se propuseram a realizar uma ação educativa em um serviço de atendimento à PVHAs.

Participaram da ação educativa aproximadamente 40 PVHAs em tratamento para a doença que se encontravam na sala de espera aguardando consulta com equipe multiprofissional em um serviço de referência em atendimento HIV/aids, localizado no município de Belém/PA. O público era composto por indivíduos de ambos os sexos e diferentes níveis de escolaridade, cuja faixa etária compreendia 18 a 61 anos, que frequentavam o serviço no turno matutino.

Uma vez que o público alvo tinha o caráter heterogêneo, elaborou-se uma tecnologia em saúde baseada em um jogo denominado de "Roleta da Saúde". A Roleta é caracterizada por um quadro confeccionado a partir de material PVC, medindo $45 \times 32 \mathrm{~cm}$, possui um círculo que roda sob um eixo no formato de roleta, este círculo é dividido em oito partes iguais no formato de triângulo, onde cada parte é discriminada por um número de $1 \mathrm{a} 4$. Na parte superior do quadro, fica uma seta que indica o número que selecionado, e na parte inferior possui 4 espaços onde são colocados as perguntas conforme o número selecionado (Figura 1).

Cada número correspondia a uma categoria temática de perguntas sobre a doença, como: 1- Conhecimentos gerais sobre HIV/aids; 2- Qualidade de vida em PVHAs; 3- Conhecimentos sobre o tratamento e adesão; 4- Mitos e verdades.

Descreve-se a seguir algumas perguntas: Como ocorre a transmissão do HIV? Por quanto tempo uma pessoa com o HIV pode sobreviver? Quem tem HIV pode praticar atividade física? Quais alimentos devo evitar e quais alimentos devo consumir com mais frequência? Por que devo tomar os medicamentos antirretrovirais? Se minha carga viral estiver indetectável, eu devo continuar tomando os medicamentos para o vírus? O HIV pode ser transmitido por picada de mosquito? O HIV pode ser transmitido pelo aleitamento materno? Após leitura da pergunta os participantes eram incentivados a respondê-las.

Antes de iniciar a dinâmica, os residentes se apresentaram aos usuários explicando a ação educativa e convidando-os a participar do momento. Posteriormente ao momento inicial de apresentação e incentivos a participação, um residente de qualquer categoria profissional sugeria que um usuário se levantasse e rodasse a roleta que se encontrava sob uma mesa, apoiada pelos residentes. Quando a roleta parava de rodar, uma seta na 


\section{ijhe}

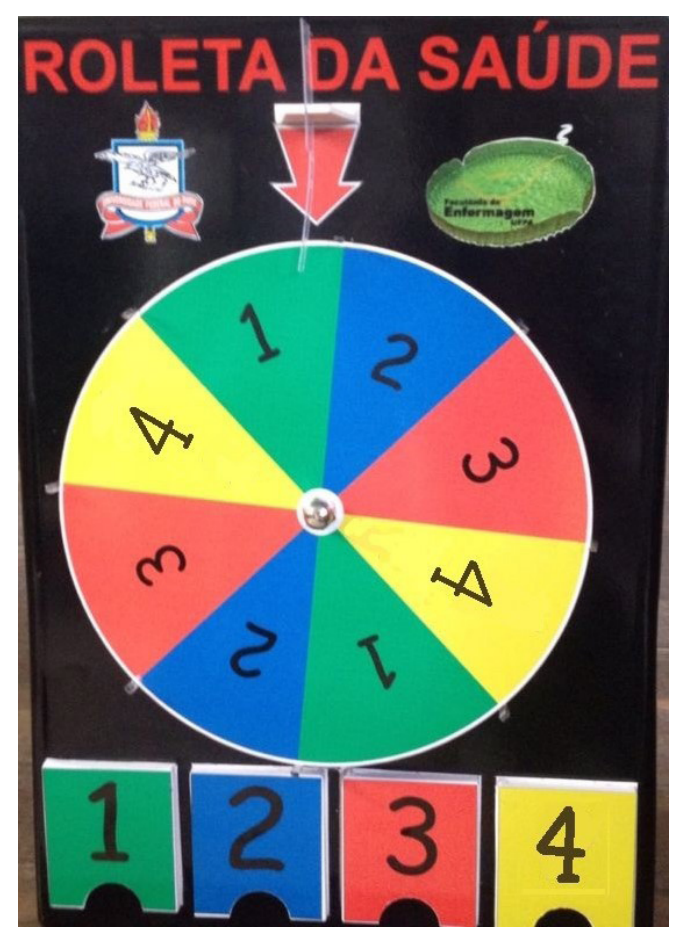

Figura 1. Fotografia da Roleta da Saúde.

parte superior indicava em qual categoria temática deveria ser respondida a pergunta. O participante em questão pegava um cartão que correspondia ao número apontado pela seta e, ao abrir o mesmo, havia uma pergunta a ser respondida; o participante ou algum residente poderia ler em voz alta a fim de que todos pudessem ouvir.

As perguntas eram feitas em uma linguagem de fácil entendimento e todos os usuários presentes na sala de espera eram incentivados a responder, e não apenas o participante que havia rodado a roleta e retirado o cartão de pergunta. Desse modo, todos se sentiam à vontade para participar da atividade e interessados em esclarecer suas dúvidas e relatar experiências. Todos eram esclarecidos sobre o caráter educativo e não coercitivo do jogo caso as respostas não fossem adequadas e reforçavam

Ao final de cada pergunta, após respostas dos envolvidos, os residentes respondiam se a resposta estava correta ou não, promovendo o aprendizado de ambas as partes, dos profissionais e usuários presentes. Cada pergunta era respondida pelos residentes que detinham competência de acordo com sua área de atuação, e assim, maiores esclarecimentos sobre a temática. A ação educativa teve uma duração de aproximadamente 1 hora durante o período da manhã.

Os usuários participantes do jogo educativo receberam "brindes" simbólicos ao final da atividade, contendo preservativos feminino e masculino como forma de salientar a importância da prevenção contra as inúmeras infecções sexualmente transmissíveis, além da entrega de folders educativos elaborados pelos próprios residentes, tratando-se do tema "(con)vivendo com HIV/aids", reforçando os assuntos abordados na ação educativa.

\section{Resultados e impactos}

O uso do jogo "Roleta da Saúde" como instrumento educativo demonstrou ser um veículo que permite interatividade e estratégia eficiente para o educar, pois possibilitou a aprendizagem de maneira significativa e a construção de conhecimentos entre os envolvidos. A partir desse jogo, foi possível verificar o entendimento dos usuários quanto a abordagem HIV/aids, ressaltando as fragilidades desses indivíduos ao conhecimento da doença de forma geral e aspectos sobre o diagnóstico, prevenção e 
terapêutica. Verificou-se que as PVHAs ainda possuem muitas dúvidas sobre o seu diagnóstico, prevenção e tratamento.

Também foi possível desconstruir alguns mitos considerados como verdades entre muitos participantes, além de reforçar durante toda a atividade a importância da adesão ao tratamento e prevenção das infecções sexualmente transmissíveis.

Destaca-se a participação espontânea do grupo durante a atividade educativa, resultando em relatos de hábitos que contribuíram para trocas de conhecimentos e experiências entre os envolvidos com muita descontração durante a espera dos atendimentos.

Em suma, a ação contribuiu para a construção do conhecimento sobre a temática $\mathrm{HIV}$ / aids, o fortalecimento da adesão ao tratamento, orientação sobre a necessidade de comportamentos e hábitos de vida saudáveis, na finalidade de melhorar o processo de autocuidado e a qualidade de vida desses usuários.

O estudo apresentou algumas limitações como: a falta de espaço adequado para realização da atividade, luminosidade, barulho, sendo a mesma realizada na sala de espera durante as consultas com equipe multiprofissional e dispersão de alguns usuários durante a atividade, visto que por vezes se mostravam preocupados em não conseguir escutar a chamada de seus nomes e o risco de perder as consultas. Por essa razão alguns usuários não quiseram participar da atividade, e com isso a dificuldade de fazê-los compreender a importância da participação na mesma. Entretanto, a maioria dos usuários teve uma boa adesão à atividade, o que reforça a viabilidade de mais ações educativas durante a sala de espera.

\section{Considerações finais}

A aplicação de tecnologia educativa como estratégia educacional em saúde para o grupo de PVHAs demonstrou-se exitosa pelo favorecimento das trocas de informações, conhecimentos e reflexão sobre o tema. Os participantes da ação educativa puderam esclarecer dúvidas e interagir de modo descontraído, facilitando a participação de todos no processo de aprendizagem.

Foi perceptível a aprovação do jogo "Roleta da Saúde" pelo grupo, pois ao se perguntar sobre a importância da ação com dinâmica, foram obtidos comentários positivos e agradecimentos pelos ensinamentos repassados. A dinâmica, ainda, proporcionou aos usuários esclarecimento de dúvidas, assim como a confirmação de conhecimentos consolidados resultantes do processo de descoberta da doença e acompanhamento ambulatorial. Dessa forma, espera-se a difusão e concretização de hábitos adequados nas atividades de vida diária desses participantes contribuindo para o sucesso do tratamento.

A ação educativa também proporcionou significativo aprendizado para os residentes envolvidos, favorecendo assim, uma formação de profissionais com visão holística do cuidar para agir ativamente na autonomia e participação efetiva das pessoas na construção do autocuidado.

\section{Referências}

1. Brasil. Ministério da Saúde. Secretaria de Vigilância em Saúde. Programa Nacional de DST/AIDS [Internet]. Brasília: 2007. [cited 2017 Dec 02]. Available from: http://www.aids.gov.br

2. Leão RNQ, et al. Aids. In: Leão RNQ, Bichara CNC, Fahira Neto H, Vasconcelos PFC, coord. Medicina Tropical e Infectologia na Amazônia. Belém: Samauma Editorial; 2013; p. 391-480.

3. Della NM, Queiroz W, Lian YC. Aids Pediátrica. In: Foccacia R, Veronesi R. Tratado de Infectologia. 5. d. 2 vol. São Paulo: Atheneu, 2015, p. 230-258.

4. Cruz RADO. Aprendizagem significativa e teatro como estratégias de prevenção do HIV em adolescentes: relatando a experiência. Rev Tend Enferm Prof [Internet]. 2013 [cited 2016 May 7];5(1):866-9. Available from: http://www.repositorio. ufc.br/ri/bitstream/riufc/7821/1/2013_art_cmrmedeiros1.pdf 
5. Brasil. Ministério da Saúde. Secretaria de Vigilância em Saúde. Boletim Epidemiológico: AIDS e DST. Brasília: Ministério

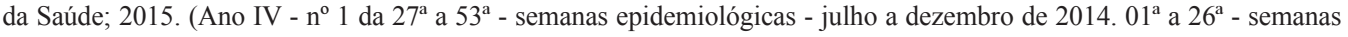
epidemiológicas - janeiro a junho de 2015).

6. Brasil. Ministério da Saúde. Secretaria de Vigilância em Saúde, Departamento de Vigilância, Prevenção e Controle das Infecções Sexualmente Transmissíveis, do HIV/Aids e das Hepatites Virais. Prevenção Combinada do HIV: bases conceituais para profissionais, trabalhadores(as) e gestores(as) de saúde. Brasília: Ministério da Saúde; 2017.

7. Pereira PS, Costa MCO, Amaral MTR, Costa HS, Silva CAL, Sampaio VS. Factors associated with HIV/AIDS infection among adolescents and young adults enrolled in a Counseling and Testing Center in the State of Bahia, Brazil. Cienc Saude Colet [Internet]. 2014. [cited 2016 Jun 12];19(3):747-58. Available from: http://www.scielo.br/pdf/csc/v19n3/1413-8123csc-19-03-00747.pdf.

8. UNAIDS: Joint United Nations Programme on HIV/AIDS [Internet]. 90- 90-90: an ambitious treatment target to the help end the AIDS epidemic. Geneve: UNAIDS; 2014 [citado em 2016 Set 11]. Disponível em: https://www.unaids.org/en/ resources/909090

9. Brasil. Ministério da Saúde. Boletim Epidemiológico AIDS/DST. [Internet]. Ano III $-\mathrm{n}^{\circ} 01.27^{\mathrm{a}}$ à $52^{\mathrm{a}}$ semanas epidemiológicas, julho a dezembro de 2013; $01^{\mathrm{a}}$ à $26^{\mathrm{a}}$ semanas epidemiológicas, janeiro a junho de 2014. Brasília: Ministério da Saúde; 2014. [citado em 2016 Jun 13]. Disponível em: http://www.aids.gov.br/pt-br/node/73

10. Grangeiro A, Castanheira ER, Nemes MIB. The reemergence of the Aids epidemic in Brazil: challenges and perspectives to tackle the disease. Interface. 2015;19(52):5-8. http://dx.doi.org/10.1590/1807-57622015.0038.

11. Freire P. Pedagogia do oprimido. São Paulo: Paz e Terra; 2006.

12. Silva LVS, Tanaka PSL, Pires MRGM. Banfisa e (In)Dica-SUS na graduação em saúde: o lúdico e a construção de aprendizados. Rev Bras Enferm [Internet]. 2015 [cited 2016 Nov 12];68(1):124-30. Available from: http://www.scielo.br/ pdf/reben/v68n1/0034- 7167-reben-68-01-0124.pdf

13. Soares ANS, Gazzinelli MF, Souza V, Araújo LHL. Role Playing Game (RPG) na graduação em enfermagem: potencialidades pedagógicas. Ver Eletr Enf. 2016;18(1):1-10.

14. Reis RK, Melo ES, Galvão MTG, Gir E. Educação em saúde junto às pessoas com HIV/AIDS: proposta de intervenção interdisciplinar. Cienc Cuid Saude, Mai;13(3):402-410. http://dx.doi.org/10.4025/cienccuidsaude.v13i3.21120.

\section{Contribuição dos autores}

Bruna Roberta Paixão dos Santos participou da concepção e desenvolvimento da pesquisa, da elaboração do desenho metodológico, da coleta e interpretação dos dados, da redação do manuscrito. Danielle Oliveira Maciel participou da concepção e desenvolvimento da pesquisa, da elaboração do desenho metodológico, da coleta e interpretação dos dados, da redação do manuscrito. Celyce Agrassar da Silva participou da concepção e desenvolvimento da pesquisa, da elaboração do desenho metodológico, da coleta e interpretação dos dados, da redação do manuscrito. Maria de Nazareth de Lima Carneiro participou da concepção e desenvolvimento da pesquisa, da elaboração do desenho metodológico, da coleta e interpretação dos dados, da redação do manuscrito. Lucas Ribeiro Brito participou da concepção e desenvolvimento da pesquisa, da elaboração do desenho metodológico, da coleta e interpretação dos dados, da redação do manuscrito. Maryllia Suellem de Almeida Cesário participou da concepção e desenvolvimento da pesquisa, da elaboração do desenho metodológico, da coleta e interpretação dos dados, da redação do manuscrito. João Gabriel Pinto Gursen participou da concepção e desenvolvimento da pesquisa, da elaboração do desenho metodológico, da coleta e interpretação dos dados, da redação do manuscrito. Elza Sara Maués Pena participou da concepção e desenvolvimento da pesquisa, da elaboração do desenho metodológico, da coleta e interpretação dos dados, da redação do manuscrito. Suzanne Camila Ferreira de Ferreira participou da coleta e interpretação dos dados e da revisão do manuscrito. Arthur dos Santos Baia participou da coleta e interpretação dos dados e da revisão do manuscrito. Mariana Zuleica Corrêa Massoud, participou da concepção e desenvolvimento da pesquisa, da elaboração do desenho metodológico, da coleta e interpretação dos dados, da redação do manuscrito. Julie Ane da Silva Formigosa participou da elaboração do desenho metodológico. Danielle Saraiva Tuma dos Reis participou da concepção e desenvolvimento da pesquisa, da elaboração do desenho metodológico, da coleta e interpretação dos dados, da redação do manuscrito. 